Article

\title{
Sustainable Valorization of Animal Manure and Recycled Polyester: Co-pyrolysis Synergy
}

\author{
Zuhal Akyürek@ \\ Department of Polymer Engineering, Faculty of Engineering and Architecture, Burdur Mehmet Akif Ersoy \\ University, 15030 Burdur, Turkey; drzuhalakyurek@gmail.com
}

Received: 5 March 2019; Accepted: 11 April 2019; Published: 16 April 2019

\begin{abstract}
In this study sustainable valorization of cattle manure, recycled polyester, and their blend (1:1 wt.\%) were examined by the thermogravimetric analysis (TGA) method. Pyrolysis tests were performed at 10,30 , and $50{ }^{\circ} \mathrm{C} / \mathrm{min}$ heating rate from room temperature to $1000{ }^{\circ} \mathrm{C}$ under a nitrogen environment with a flow of $100 \mathrm{~cm}^{3} / \mathrm{min}$. Kinetics of decomposition were analyzed by using Flynn-Wall-Ozawa (FWO) method. Based on activation energies and conversion points, a single region was established for recycled polyester while three regions of pyrolysis were obtained for cattle manure and their blend. Comparison between experimental and theoretical profiles indicated synergistic interactions during co-pyrolysis in the high temperature region. The apparent activation energies calculated by FWO method for cattle manure, recycled polyester and their blend were 194.62, 254.22 and $227.21 \mathrm{~kJ} / \mathrm{mol}$, respectively. Kinetics and thermodynamic parameters, including $\mathrm{E}, \Delta \mathrm{H}$, $\Delta \mathrm{G}$, and $\Delta \mathrm{S}$, have shown that cattle manure and recycled polyester blend is a remarkable feedstock for bioenergy.
\end{abstract}

Keywords: co-pyrolysis; cattle manure; recycled polyester; thermogravimetric analysis; kinetics; thermodynamic parameters; waste management; sustainable energy

\section{Introduction}

Environmental impacts of fossil fuels used for power generation is a worldwide concerning topic. Integration of sustainable energy and carbon capture technologies have been steadily increasing in both capacity and number to reduce adverse effects of fossil fuels on global climate change. Biomass is one of the emerging alternatives for the diversification of worldwide energy sources [1]. Biomass is the only renewable carbon resource that can be directly converted into fuel [2]. Especially in the last decade it has attracted more attention as a low risk and capital required renewable energy source [3-6]. Biomass is an abundant energy resource accounting for $9 \%$ of electricity consumption in the world in 2015. Furthermore, biomass resources are estimated to supply 15-25\% (130-270 EJ/year) of the world's primary energy demand in 2050 [7].

In many developing countries, most of the biomass including animal manure are used for soil amendment purposes or disposed directly of on the fields. These applications trigger global environmental pollution, non-carbon dioxide greenhouse gas emissions such as methane and nitrous oxide, surface and ground water contamination [8,9], and antibiotic resistance [10]. Turkey has a very large biomass potential of 8.6 MTOE generated by agricultural, animal, and urban wastes. Livestock manure is an abundant biomass resource in Turkey. More than 157 million tons/year of animal manure stock involve renewable energy potential equivalent to about 1.3 MTOE/year [11].

The production of plastics on the other hand, has continuously increased in the last decades due to their wide application in several sectors, such as packaging, building, automotive, electric and electronics, and agriculture industries, etc. Plastics are highly durable, strong, elastic, and inexpensive materials. Therefore, plastic products have become another important waste management issue due to 
their large amount and long life span varying within the range of weeks to several years to degrade naturally in the environment leading to serious environmental pollution [12]. Moreover, plastics are manufactured from petroleum derivatives. They contain high calorific value materials, therefore, there is immediate need to reuse them productively for both managing waste and saving fossil fuel reserves. The uncontrolled incineration of waste plastics is a hazardous source of air pollution, which is responsible for the release of dioxins, furans, mercury, and polychlorinated biphenyls into the atmosphere [13]. In Europe, about $20.3 \%$ of the plastic waste was landfilled, $40.9 \%$ were recycled while $38.8 \%$ were utilized for energy recovery in 2017 [14]. In Turkey about $24 \%$ of the plastic wastes are recovered for recycling annually [15].

In view of above issues, there is an urgent need to develop sustainable waste management strategies to protect the environment and human health by reducing waste volume and converting waste materials into green energy and high value added products through clean thermochemical conversion technologies [16,17]. Pyrolysis is a well-known thermochemical conversion technology for waste disposal that is being developed to convert waste materials into energy and valuables, such as bio-oil, synthetic gas, and biochar products $[4,18]$. It is an attractive way of extracting biomass energy to produce stabilized pyrolysis oil which has potential to be used as fuels in furnaces, turbines, and diesel engines or feedstock for many chemicals; combustible syngas for power generation; and biochar to be used as soil fertilizer and green adsorbent [19].

The product yields vary depending on the process parameters and waste structure [20]. Extensive knowledge of these processes require an adequate understanding of kinetics of thermal decomposition process. Thermogravimetric analysis (TGA) is a simple and highly precise technique extensively used to investigate the decomposition and kinetic behavior of different fuels with respect to temperature [21,22].

Even through many studies have been carried out on pyrolysis of biomass, the issue has remained complicated due to fact that the process strongly depends on biomass structure, fuel mix, and experimental conditions. Lignocellulosic biomass contains cellulose (32-45\%), hemicellulose (19-25\%), and lignin (14-26\%) [22]. Hemicellulose has a branched structure and degrades easily at $220-315{ }^{\circ} \mathrm{C}$. Cellulose is composed of a linear chain polysaccharide having higher thermal resistance with respect to hemicellulose. Its thermal degradation takes place in the temperature range of 315 to $400^{\circ} \mathrm{C}$. Lignin is a more complex polymeric structure decomposing in a broader temperature range of $150-900^{\circ} \mathrm{C}[23,24]$. Cellulose is mainly responsible for syngas yield; lignin is the main contributor of char yield while hemicellulose has equal contribution to both [2].

Plastics on the other hand, are rich in hydrogen compounds. The common feature of plastic waste is the high volatile content, high viscosity with low melting points and high energy density due to very low moisture and ash contents [25]. Plastics are highly suitable for co-pyrolysis with biomass in order to improve compound diversity and quality [26]. Biomass and plastics are comprised of different monomers. The $\mathrm{H} / \mathrm{C}$ and $\mathrm{O} / \mathrm{C}$ of the monomers involved can help one to better understand their non-linear interactions during decomposition. $\mathrm{OH}$ and $\mathrm{H}$ radicals help cracking of aromatic compounds and promotes the gaseous yield [27].

Although there is vast literature on the pyrolysis of biomass- and plastic-derived materials, research on the use of biomass and plastics for producing fuels and chemicals using the co-pyrolysis process is less apparent. When biomass is pyrolyzed alone, the product oil and syngas have high oxygen content and low calorific value. The pyrolysis oil requires upgrading with methods such as hydrogenation, catalytic cracking, steam reforming, esterification, etc., to be qualified. Recently, co-pyrolysis of biomass with hydrogen-rich feedstock of higher fuel qualities, such as synthetic polymers/plastics, have attracted interest. As a simple and economic process for producing high quality fuels, co-pyrolysis of biomass and plastics has been regarded as an effective method to upgrade the bio-oils and syngas. Synergistic effects of biomass-plastics co-pyrolysis have also resulted in non-additive increase in syngas yields. Non-additive enhancement of carbon conversion yield, syngas, and bio-oil quality make co-pyrolysis a favorable route for sustainable development of the biomass energy industry $[28,29]$. 
In order to study the technical feasibility of co-pyrolysis it would be necessary to assess the possible synergetic effects of biomass and plastic blends on the pyrolysis product properties. In the literature, for instance, thermal behavior and kinetic analysis of biomass blending with plastics, such as rice straw [30], corn stover [31], sawdust [26], animal manure [32], municipal solid waste [33], olive residue [34], and pine wood [35], etc., were reported.

Co-pyrolysis of biomass with waste plastics is a simple and cost-effective solution to waste management and to reduce dependency on fossil resources. As waste materials have various species and non-uniform structure, they exhibit different pyrolytic characteristics. The synergism in co-pyrolysis is seen as an increase in product yield, improvement in product characteristics, and decrease in emissions [21]. In many studies synergy during co-pyrolysis has depicted by the higher weight loss than the theoretical values calculated via a weighted average of single materials $[3,36]$. In some studies, however, a negative impact of co-pyrolysis on volatiles yields has observed [37]. Therefore, it is difficult to predict the thermal behavior of biomass and plastic blends. To the best of the authors' knowledge, no study has been published about thermal behavior during co-pyrolysis of cattle manure and recycled polyester.

In the present study, the thermal and kinetic behavior of cattle manure $(\mathrm{CM})$ and recycled polyester (RP) and their blend are investigated in TGA. Pyrolysis and co-pyrolysis experiments were performed in nitrogen flow of $100 \mathrm{~mL} / \mathrm{min}$, with 10,30 and $50{ }^{\circ} \mathrm{C} / \mathrm{min}$ heating rate from room temperature to $1000^{\circ} \mathrm{C}$. Cattle manure has pyrolyzed alone and together with recycled polyester (1:1, wt. $\%$ blending). Kinetic study of pyrolysis process is useful for optimizing operation of the thermochemical conversion of biomass feedstock. The pyrolysis kinetics were described by the Flynn-Wall-Ozawa (FWO) integration method. Kinetic parameters, such as activation energy and pre-exponential factor of the pyrolysis mechanism, were derived with the obtained TGA data. Thermodynamic properties $(\Delta H, \Delta G, \Delta S)$ have also been calculated using the TGA data.

\section{Materials and Methods}

\subsection{Raw Materials}

High economic value of livestock farming in Turkey signify the availability of livestock manure potential for energy production. In this study cattle manure and recycled polyester were used as raw materials. Manure was obtained from a local cattle farm in Ağlasun, Burdur, Turkey. The sample was dried in oven overnight at $80^{\circ} \mathrm{C}$ and then was sifted out $0.5-1 \mathrm{~mm}$ size. Recycled polyester fabric was supplied from Hürsan Textile Inc., Denizli, Turkey. Fabric samples were cut into the similar size with cattle manure. The primary analyses of the samples are shown in Table 1. Moisture, volatile matter, ash contents of the samples were determined by ASTM D3173, ASTM D 3175, and ASTM D 3174, respectively. The major elements $(\mathrm{C}, \mathrm{H}, \mathrm{N}, \mathrm{S})$ were tested by a LECO CHNS-932 (Leco Corp., St. Joseph, MI, USA) elemental analyzer and the content of $\mathrm{O}$ was calculated by the difference.

Table 1. Proximate and ultimate analysis of cattle manure (CM) and recycled polyester (RP) samples.

\begin{tabular}{|c|c|c|}
\hline \multicolumn{3}{|c|}{ Proximate Analysis (As Received Basis) } \\
\hline & $\mathrm{CM}$ & $\mathbf{R P}$ \\
\hline Moisture,\% & 7.75 & 0.62 \\
\hline Volatile Matter,\% & 54.55 & 87.19 \\
\hline Fixed Carbon,\% & 12.40 & 12.15 \\
\hline Ash, $\%$ & 25.30 & 0.04 \\
\hline \multicolumn{3}{|c|}{ Ultimate Analysis (Dry Basis) } \\
\hline $\mathrm{C}, \%$ & 33.07 & 62.8 \\
\hline $\mathrm{H}, \%$ & 4.87 & 4.3 \\
\hline $\mathrm{N}, \%$ & 2.90 & 0.07 \\
\hline $\mathrm{S}, \%$ & 0.63 & 0.04 \\
\hline $\mathrm{O}, \%$ (by difference) & 58.53 & 32.79 \\
\hline LHV $(\mathrm{kJ} / \mathrm{kg})$ & 11.20 & 20.57 \\
\hline
\end{tabular}


The lower heating values (LHV) of the fuels based on element analysis generally is estimated by the following equation [38];

$$
L H V(\mathrm{MJ} / \mathrm{kg})=-6.1755+0.3894 \mathrm{C}+0.6107 \mathrm{H}+3.78 \mathrm{~S}-0.01468 \mathrm{O}
$$

\subsection{Thermogravimetric Analysis}

Thermogravimetric (TG) and derivative thermogravimetric (DTG) analysis experiments of the cattle manure and recycled polyester fabric were carried out using a TG analyzer (Seiko SII TG/DTA 7200 , Hitachi Corp., Japan) under a nitrogen atmosphere, heated from room temperature to $900-1000^{\circ} \mathrm{C}$. The experiments were performed at three different heating rates of 10,30 , and $50{ }^{\circ} \mathrm{C} / \mathrm{min}$ for each sample. The sample weight was kept at about $10 \mathrm{mg}$. Nitrogen gas was used for pyrolysis with a flow rate of $100 \mathrm{~mL} / \mathrm{min}$ to ensure an inert atmosphere on the sample during the run.

\subsection{Kinetic Study}

Pyrolysis kinetics of biomass can be expressed according to the Arrhenius relation, $k(T)$ as:

$$
k(T)=A \exp \left(\frac{-E}{R T}\right)
$$

where $T(K)$ is the absolute temperature, $k(T)$ is the reactivity (the rate constant) depending on the temperature, A (s-1) is the pre-exponential factor, $\mathrm{E}(\mathrm{J} / \mathrm{mol})$ is the activation energy, and $\mathrm{R}$ is the universal gas constant $(8.314 \mathrm{~J} / \mathrm{mol} \mathrm{K})$.

The kinetics of heterogeneous solid-state thermal degradation is dominated by the fundamental equation:

$$
\begin{gathered}
\frac{d \alpha}{d t}=k(T) f(\alpha) \\
\frac{d \alpha}{d t}=A \exp \left(\frac{-E_{A}}{R T}\right) f(\alpha)
\end{gathered}
$$

where $t$ is the time, $f(\alpha)$ is the reaction function depending on the conversion rate $\alpha$ in relation to reaction model, at the conversion degree $\alpha$.

The conversion for pyrolysis is described as:

$$
\alpha=\frac{W_{0}-W_{t}}{W_{0}-W_{f}}
$$

where $W_{0}$ and $W_{f}$ are the initial and final weight of the sample, respectively. And $W_{t}$ is the weight of the sample at temperature $\mathrm{T}$.

Pyrolysis reactivity index $\left(R_{i}\right)$ is calculated according to the following formula:

$$
R_{i}=\frac{1}{w_{0}}\left(\frac{d w}{d t}\right)_{\max }
$$

where $(d w / d t)_{\max }$ is the maximum pyrolysis rate. The raw material has a better reactivity when it has a greater reactivity index.

Heating rate $\beta(\mathrm{K} / \mathrm{min})$ is defined as:

$$
\beta=\frac{d T}{d t}
$$

Equation (2) can be transformed into:

$$
\frac{d \alpha}{d T}=\frac{A}{\beta} \exp \left(\frac{-E_{A}}{R T}\right) f(\alpha)
$$


The integrated form of $f(\alpha)$ is generally expressed as:

$$
G(\alpha)=\int_{0}^{\alpha} \frac{d(\alpha)}{f(\alpha)}=\frac{A}{\beta} \int_{T_{0}}^{T} \exp \left(\frac{-E}{R T}\right) d T
$$

It is well-known that the iso-conversional method provides feasible methods for estimation of activation energy because of their good adaptability and validity for model-free approaches. Flynn-Wall-Ozawa (FWO) [39,40] introduced a linear correlation for a given value of conversion at different heating rates. FWO kinetic method is described as:

$$
\operatorname{In} \beta=\operatorname{In} \frac{A E_{a}}{\operatorname{Rg}(\alpha)}-5.331-1.052 \frac{E_{a}}{R T}
$$

The apparent activation energy can be calculated from the plot of $I n \beta$ vs. $1 / \mathrm{T}$ for a given value of conversion where the slope is equal to $-1.052 \mathrm{Ea} / \mathrm{R}$. FWO integration method is used in this study for determination of the pyrolysis kinetics of cattle manure, recycled polyester, and their blend.

The pre-exponential factors (A) and other thermodynamic parameters such as Enthalpy $(\Delta H)$, Gibbs free energy $(\Delta G)$, and entropy $(\Delta S)$ were calculated by Equations (10)-(13);

$$
\begin{gathered}
A=\beta \cdot E_{a} \cdot \exp \left(\frac{E_{a}}{R \cdot T_{\max }}\right) \cdot \frac{1}{R \cdot T_{\max }^{2}} \\
\Delta H=E_{a}-R T \\
\Delta G=E_{a}+R \cdot T_{\max } \cdot \operatorname{In}\left(\frac{K_{b} \cdot T_{\max }}{h \cdot A}\right) \\
\Delta S=\frac{\Delta H-\Delta G}{T_{\max }}
\end{gathered}
$$

where $T_{\max }$ is the peak temperature, $\mathrm{Kb}$ is the Boltzmann constant $\left(1.381 \times 10^{-23} \mathrm{~J} / \mathrm{K}\right)$ and $\mathrm{h}$ is the Plank constant $\left(6.626 \times 10^{-34} \mathrm{Js}\right)$.

\section{Results}

\subsection{Pyrolysis and Co-Pyrolysis of Cattle Manure (CM) and Recycled Polyester}

Thermogravimetric analysis provides understanding of the thermal decomposition and reaction mechanism during pyrolysis process. The TG curves indicate the mass loss of the sample with respect to temperature change during thermal degradation, and the DTG curves show the corresponding rates of mass loss of the TG curves. Pyrolytic behavior of the cattle manure and recycled polyester were illustrated with the mass loss (TG) and derivative mass loss (DTG) curves, in Figures 1 and 2, respectively, under different heating conditions.

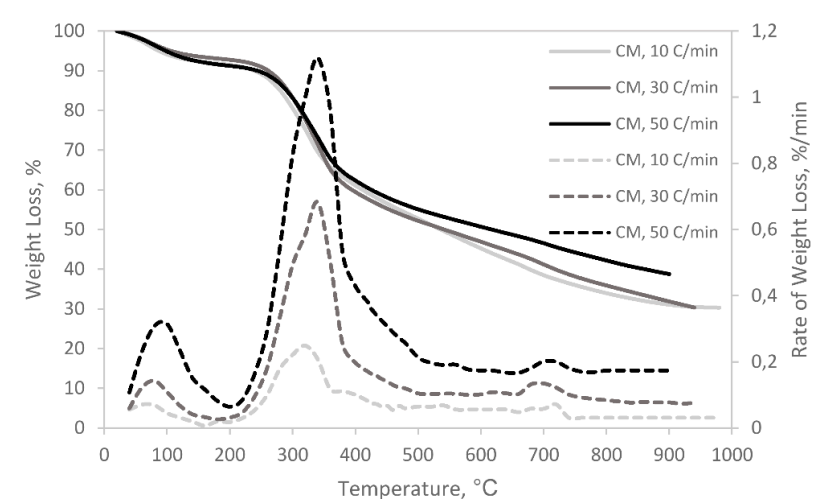

Figure 1. Weight loss and derivative weight loss vs. temperature of $\mathrm{CM}$ at 10,30 , and $50^{\circ} \mathrm{C}$ heating rates. 


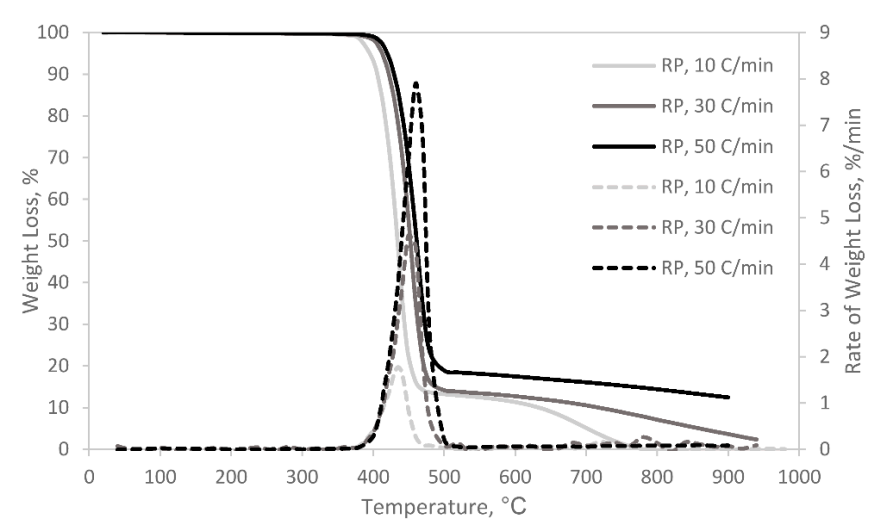

Figure 2. Weight loss and derivative weight loss vs. temperature of $\mathrm{RP}$ at 10,30 , and $50^{\circ} \mathrm{C}$ heating rates.

TGA and DTG profiles were used to determine pyrolysis behavior and characteristic temperatures, such as the initial decomposition temperature $\left(T_{\text {in }}\right)$, peak temperature $\left(T_{\max }\right)$, final temperature $\left(T_{f}\right)$, and $R_{\max }$ is the maximum reactivity value. Pyrolysis and co-pyrolysis characteristics of the wastes are shown in Table 2.

Table 2. Pyrolysis and co-pyrolysis characteristics of CM, RP and their blend.

\begin{tabular}{|c|c|c|c|c|c|c|}
\hline Sample & $\begin{array}{l}\text { Heating Rate } \\
\left({ }^{\circ} \mathrm{C} / \mathrm{min}\right)\end{array}$ & $\begin{array}{c}\mathrm{T}_{\mathrm{i}} \\
\left({ }^{\circ} \mathrm{C}\right)\end{array}$ & $\begin{array}{l}\mathrm{T}_{\max } \\
\left({ }^{\circ} \mathrm{C}\right)\end{array}$ & $\begin{array}{c}\mathrm{T}_{\mathrm{f}} \\
\left({ }^{\circ} \mathrm{C}\right)\end{array}$ & $\begin{array}{c}R_{\max } \\
\text { (\%/min.mg) }\end{array}$ & $\begin{array}{l}\text { Total Weight } \\
\text { Loss, } \%\end{array}$ \\
\hline \multicolumn{7}{|l|}{$\mathrm{CM}$} \\
\hline & 10 & 231.1 & 339.3 & 523.7 & 0.041 & 69.7 \\
\hline & 30 & 236.3 & 344.6 & 557.1 & 0.110 & 67.4 \\
\hline & 50 & 239.3 & 348.9 & 566.4 & 0.138 & 61.2 \\
\hline \multicolumn{7}{|l|}{ RP } \\
\hline & 10 & 384.9 & 436.5 & 470.5 & 0.533 & 99.2 \\
\hline & 30 & 401.8 & 457.8 & 499.5 & 0.609 & 89.9 \\
\hline & 50 & 409.5 & 462.7 & 521.7 & 0.980 & 89.5 \\
\hline \multicolumn{7}{|c|}{ Blend (1:1 wt.\%) } \\
\hline & 10 & 223.9 & 433.4 & 522.4 & 0.102 & 83.3 \\
\hline & 30 & 252.2 & 435.8 & 520.6 & 0.276 & 80.1 \\
\hline & 50 & 261.8 & 436.4 & 502.9 & 0.419 & 73.3 \\
\hline
\end{tabular}

In order to get an overall understanding of the potential synergistic effects of co-pyrolysis of the manure and recycled plastics, the theoretical and experimental thermogravimetric analysis values of the blends have compared. The theoretical values of the blends in the pyrolysis was computed by the weighted-average sum of the individual sample's experimental values (Figure 3).

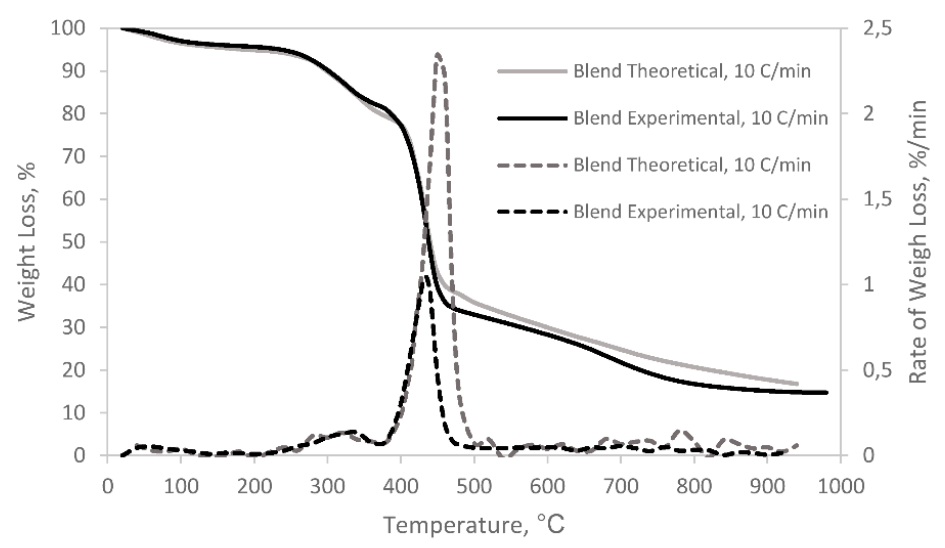

(a)

Figure 3. Cont. 


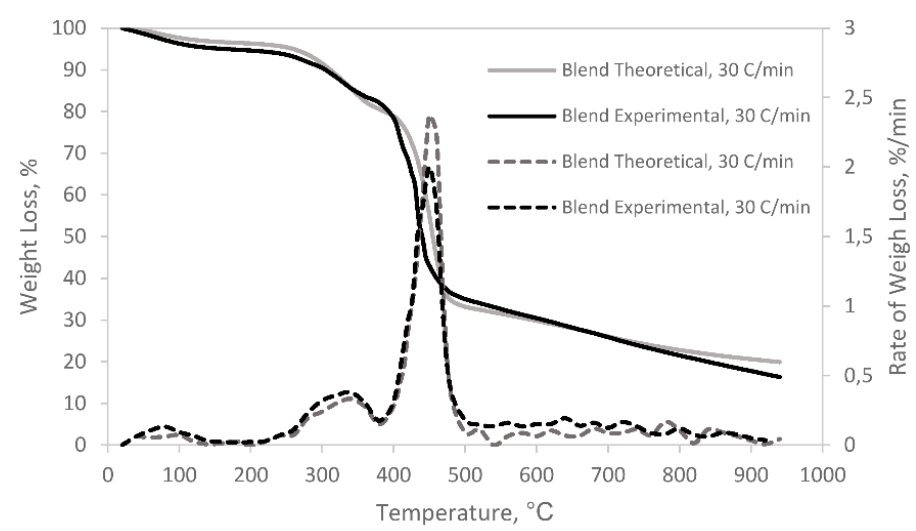

(b)

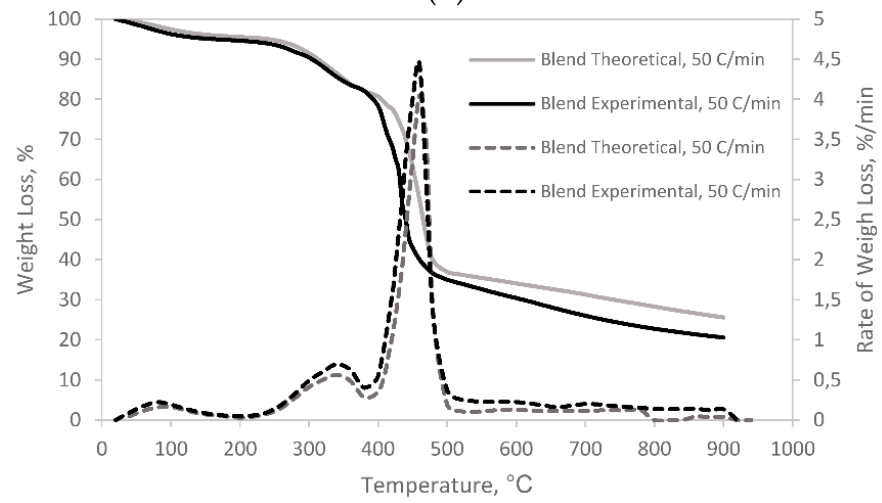

(c)

Figure 3. Comparison of theoretical and experimental data of co-pyrolysis of $\mathrm{CM}$ and RP blend (a) at a $10^{\circ} \mathrm{C}$ heating rate, $(\mathbf{b})$ at a $30{ }^{\circ} \mathrm{C}$ heating rate, and $(\mathbf{c})$ at a $50{ }^{\circ} \mathrm{C}$ heating rate.

\subsection{Kinetic Analysis}

Flynn-Wall-Ozawa (FWO) was used for fitting the DTGs of pyrolysis of cattle manure and recycled polyester (Figure 4). Kinetic parameters calculated using Equation (9) are shown in Table 3. Activation energy can be defined as the reactivity of a fuel in other terms the minimum amount of energy required to start a reaction [22]. As can be seen from Table 3, the activation energy of cattle manure increased by increasing conversion. This is indicative of the presence of endothermic reactions.

Table 3. Kinetic parameters for the pyrolysis of cattle manure, recycled polyester, and their blend.

\begin{tabular}{cccccccc}
\hline Sample & $\begin{array}{c}\text { Conversion } \\
\mathbf{\%}\end{array}$ & $\begin{array}{c}\mathbf{E}_{\mathbf{a}} \\
(\mathbf{k J} / \mathbf{m o l})\end{array}$ & $\begin{array}{c}\mathbf{A} \\
\left(\mathbf{s}^{\mathbf{- 1}}\right)\end{array}$ & $\mathbf{R}^{\mathbf{2}}$ & $\begin{array}{c}\mathbf{\Delta H} \\
(\mathbf{k J} / \mathbf{m o l})\end{array}$ & $\begin{array}{c}\Delta \mathbf{G} \\
(\mathbf{k J} / \mathbf{m o l})\end{array}$ & $\begin{array}{c}\Delta \mathbf{S} \\
(\mathbf{J} / \mathbf{m o l} \mathbf{K})\end{array}$ \\
\hline \multirow{4}{*}{$\mathbf{C M}$} & 0.2 & 151.16 & $6.31 \times 10^{10}$ & 0.9935 & 146.07 & 178.20 & -52.46 \\
& 0.3 & 159.04 & $3.12 \times 10^{11}$ & 0.9958 & 153.95 & 145.26 & 14.18 \\
& 0.4 & 169.61 & $2.65 \times 10^{12}$ & 0.9927 & 164.52 & 144.94 & 31.97 \\
& 0.5 & 175.15 & $8.12 \times 10^{12}$ & 0.9986 & 170.06 & 144.77 & 41.28 \\
& 0.6 & 181.54 & $2.96 \times 10^{13}$ & 0.9978 & 176.45 & 144.58 & 52.03 \\
& 0.7 & 210.14 & $9.41 \times 10^{15}$ & 0.9946 & 205.05 & 155.57 & 80.79 \\
& 0.8 & 315.72 & $1.43 \times 10^{25}$ & 0.9972 & 310.63 & 141.77 & 275.71 \\
$\mathbf{R P}$ & Average & 194.62 & & & 189.53 & 150.73 & 109.22 \\
& 0.2 & 301.98 & $2.04 \times 10^{25}$ & 0.9989 & 296.08 & 218.57 & 116.53 \\
& 0.3 & 255.84 & $6.92 \times 10^{16}$ & 1.0000 & 249.94 & 167.25 & 110.83 \\
& 0.4 & 251.89 & $3.50 \times 10^{16}$ & 0.9995 & 245.99 & 167.34 & 123.70 \\
& 0.5 & 260.83 & $1.64 \times 10^{17}$ & 0.9977 & 254.93 & 167.15 & 92.51 \\
& 0.6 & 239.19 & $3.85 \times 10^{15}$ & 1.0000 & 233.29 & 167.65 & 81.62 \\
\hline
\end{tabular}


Table 3. Cont.

\begin{tabular}{lccccccc}
\hline & 0.8 & 224.93 & $3.23 \times 10^{14}$ & 0.9942 & 219.03 & 168.00 & 71.90 \\
& Average & 254.22 & & & 248.32 & 176.72 & \\
\hline & 0.2 & 271.03 & $1.19 \times 10^{18}$ & 0.9971 & 265.16 & 204.66 & 85.63 \\
Blend & 0.3 & 212.72 & $4.55 \times 10^{13}$ & 0.9987 & 206.84 & 167.55 & 55.61 \\
$\mathbf{( 1 : 1 ~ w t . \% )}$ & 0.4 & 211.37 & $3.59 \times 10^{13}$ & 0.9981 & 205.49 & 167.59 & 53.64 \\
& 0.5 & 233.19 & $1.62 \times 10^{15}$ & 0.9973 & 227.29 & 167.01 & 85.31 \\
& 0.6 & 206.35 & $1.49 \times 10^{13}$ & 0.9956 & 200.47 & 167.74 & 46.33 \\
& 0.7 & 212.72 & $4.55 \times 10^{13}$ & 0.9997 & 206.84 & 181.08 & 36.46 \\
& 0.8 & 218.65 & $1.70 \times 10^{16}$ & 0.9903 & 240.78 & 166.70 & 104.85 \\
\hline
\end{tabular}

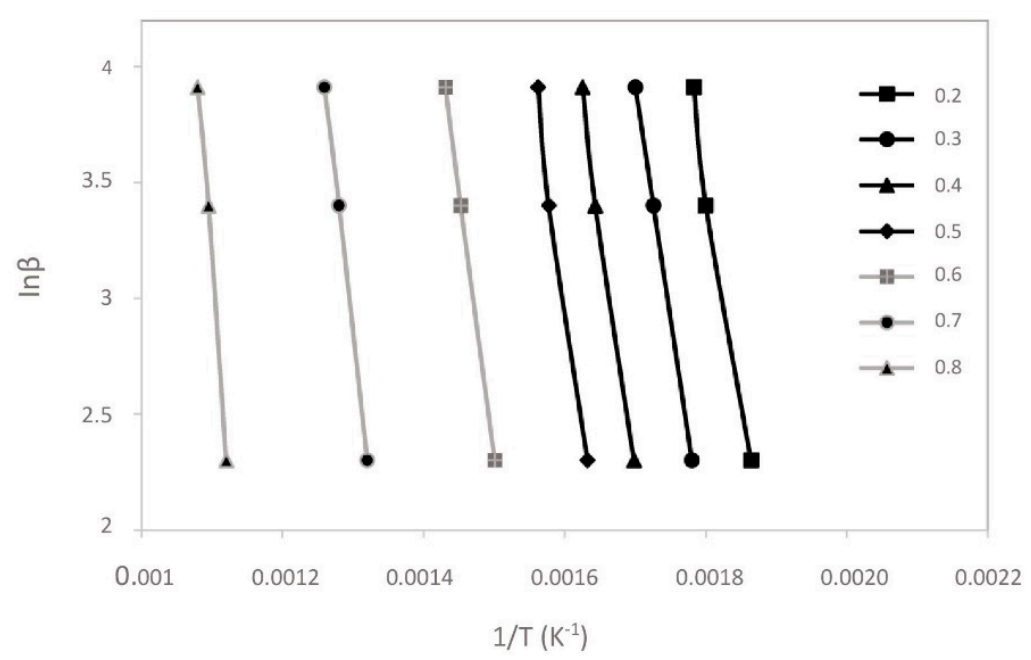

(a)

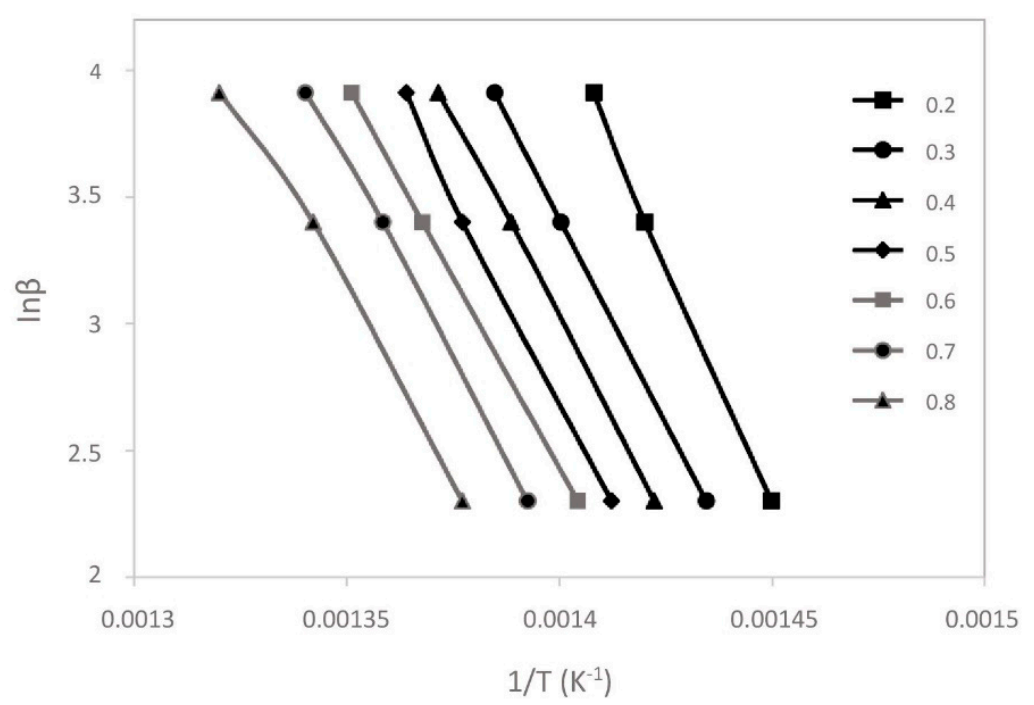

(b)

Figure 4. Cont. 


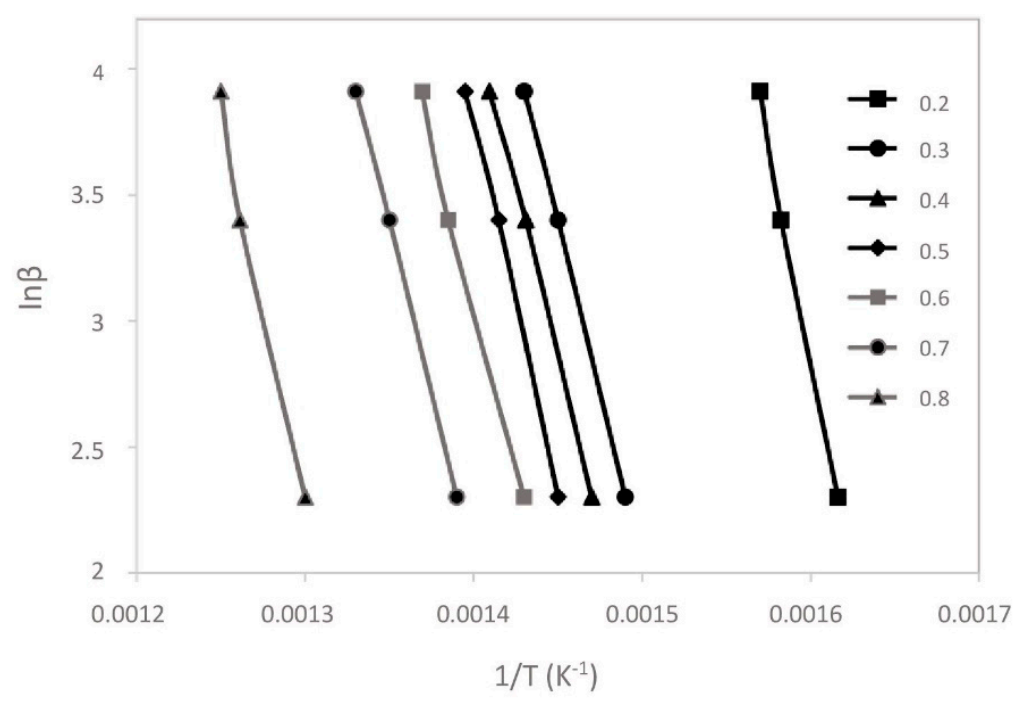

(c)

Figure 4. Linear correlation for determining activation energy of (a) CM, (b) RP, and (c) CM/RP Blend calculated by FWO.

In order to investigate the possible interactions on energy barrier, the variation of activation energies of the waste materials and their blend were illustrated in Figure 5 with corresponding conversion degrees.

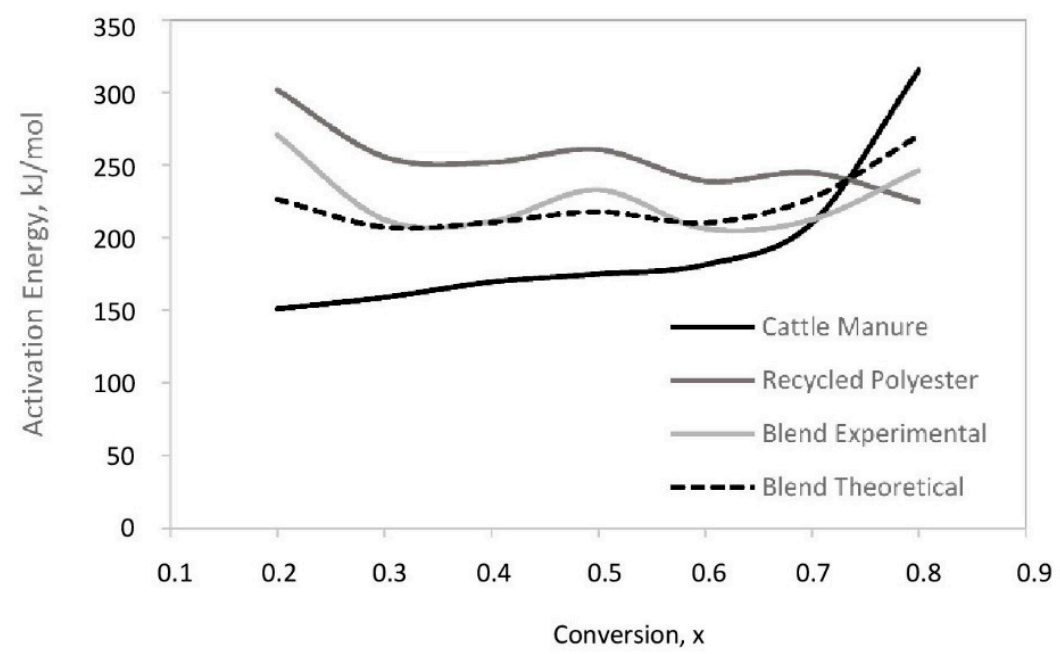

Figure 5. Plots of activation energy with respect to conversion.

\subsection{Pyrolysis Thermodynamics}

Equations (10) - (13) were used to calculate the thermodynamic parameters and the results are presented in Table 3. According to the discussion above, the apparent activation energies $\left(\mathrm{E}_{\mathrm{a}}\right)$ derived from FWO method (see Table 3) were used to calculate the thermodynamic parameters of $A, \Delta H, \Delta G$, and $\Delta \mathrm{S}$. As, the interactions among the constituents increases with heating rate during the pyrolysis process [4] the lowest heating rate of $10^{\circ} \mathrm{C} / \mathrm{min}$ was used for calculation of pre-exponential factors.

\section{Discussion}

In this study, thermogravimetric analysis was used to evaluate the thermal degradation and reaction mechanism of pyrolysis and co-pyrolysis process. It can be seen from the Figures 1 and 2 that thermal decomposition of cattle manure and recycled polyester was different from each other. 
Cattle manure was decomposed at lower temperatures than recycled polyester due to a less complicated structure of plastics compared to that of biomass. In addition, the moisture-free feature of plastics resulted in faster decomposition at higher temperatures.

Decomposition of manure is a complex process due to varying chemical characteristics of the waste material components [41]. Biomass devolatilization has occurred in the temperature range of $200-400{ }^{\circ} \mathrm{C}$ while recycled polyester devolatilized in the temperature range of $300-500{ }^{\circ} \mathrm{C}$ similar to other plastic materials [42]. This indicates that recycled polyester is more difficult to decompose when compared with manure. Manure has stayed stable until $200{ }^{\circ} \mathrm{C}$, with minor moisture loss and the hydrolysis of some extractives (e.g. proteins, starches, lipids, sugars, etc.) different from of agro-biomass $[4,43]$. The first peak below $200^{\circ} \mathrm{C}$ demonstrated the weight loss due to the release of inherent moisture in cattle manure. Based on the literature data [36], the second DTG peak in between 200 and $400{ }^{\circ} \mathrm{C}$ was associated with the rapid decomposition of hemicellulose and cellulose and the shoulder shape in between 400 and $550^{\circ} \mathrm{C}$ was depicted decomposition of lignin. The third peak at $700-750{ }^{\circ} \mathrm{C}$ was attributed due to the decomposition of the residues. Similar trends were also observed in manure pyrolysis $[41,44]$. After $750^{\circ} \mathrm{C}$, the DTG curve has stabilized and the final residue has stayed in the range of $30-40 \%$. The amount of the residual weight has found to be in good agreement with the proximate analysis, reflecting the total amount of fixed carbon and ash in biomass [45]. The heating rate is an important factor on biomass pyrolysis. The maximum temperature has observed to shift towards higher values by increasing the heating rate as expected (Figure 1).

Pyrolysis of recycled polyester under similar conditions was also conducted to obtain the pyrolytic characteristics of pure polyester before blending with cattle manure. In the TGA curve of recycled polyester (Figure 2), one main peak has occurred representing the weight loss with respect to the increase in temperature. Highly oxygenated bonding was responsible for one stage degradation of polyesters [46]. The structural breakdown of recycled polyester fabric has started about $385^{\circ} \mathrm{C}$ and the maximum weight loss has occurred at $436.5^{\circ} \mathrm{C}$. About $70 \%$ of the weight loss has completed at $440^{\circ} \mathrm{C}$. This data is in correspondence with the TGA data given for thermoplastic decomposition [28,47]. The residual weight during thermal decomposition of recycled polyester has found to be negligible indicating occurrence of stronger reactions compared to degradation of biomass during decomposition [48]. Similar to manure pyrolysis the TGA curve of recycled polyester has shifted to the higher temperature with the increase in heating rate.

During co-pyrolysis, thermoplastic materials has melted without changing their chemical composition before the structural decomposition [28]. This has resulted in good mixing of recycled polyester with cattle manure during pyrolysis. The thermal decomposition of recycled polyester has shifted to lower temperatures and the DTG curves have become broader in the presence of cattle manure.

Comparison of the theoretical and experimental co-pyrolysis data revealed positive synergy between the manure and recycled polyester. Synergy has led to different results than those obtained from individual materials. As seen from the TG data in Figure 3, higher weight loss has occurred during co-pyrolysis than the theoretical values calculated from single waste materials. Addition of recycled polyester to cattle manure increased the rate of volatile evolution during biomass decomposition and lowered the peak corresponding to pyrolysis compared to the weighted DTG. The weighted conversion rate for recycled polyester revealed a decrease in the peak of pyrolysis expected between $375{ }^{\circ} \mathrm{C}$ and $480^{\circ} \mathrm{C}$, a decrease in the manure pyrolysis peak at around $350{ }^{\circ} \mathrm{C}$. This finding has supported the presence of synergistic interaction on the solid phase causing loss in weight. Benzyl radicals of plastic materials as discussed earlier interacted with the biomass volatiles created such synergy which also enhanced the carbon conversion efficiency [28]. The increase in the heating rates has shifted the maximum peak temperatures to the higher values without changing thermal profiles during co-firing.

As shown in Table 3, $R^{2}$ of all the curves was within the narrow interval of 0.9903 to 1.000 from conversion of $0.2-0.8$. This was an indicative of well-correlation of pyrolysis and co-pyrolysis of cattle manure and recycled polyester with FWO approach (Figure 4). Variation of activation energies at 
different conversion degrees suggested multistage thermal degradation of cattle manure and recycled plastics and complexity of the degradation process. The cattle manure degraded in three stages, whereas the recycled polyester has degraded within one main stage. The highest apparent activation energy for cattle manure pyrolysis has occurred in the third stage as $315.72 \mathrm{~kJ} / \mathrm{mol}$ at a conversion degree of 0.8 and at about $615^{\circ} \mathrm{C}$. For recycled polyester on the other hand, the highest activation energy has obtained in the first stage at 0.2 conversion degree and $275^{\circ} \mathrm{C}$ temperature as $301.98 \mathrm{~kJ} / \mathrm{mol}$. The mean activation energies for cattle manure $[4,41]$ and polyester $[49,50]$ degradation have found to be in correspondence with previous studies.

The experimental results were compared with theoretical results obtained from linear calculation of individual manure and polyester degradation. As seen from Figure 5, co-pyrolysis has reduced the apparent activation energy of recycled polyester suggesting decrease in energy consumption for pyrolysis. The comparison of experimental and theoretical activation energies revealed non-additive behavior suggesting synergy in co-pyrolysis. This finding is in correspondence with the findings of previous studies on co-pyrolysis of biomass with plastics $[37,50]$. The activation energy of the blend has followed similar trend with recycled polyester, but at lower values until $70 \%$ of conversion degree.

As can be seen from Table $3, \Delta \mathrm{H}$ value has increased with the increasing of conversion degree. The enthalpy of reaction can be defined as the amount of energy exchanged in a chemical reaction or the energy required for thermal degradation of the feedstock. In pyrolysis process, enthalpy describes the amount of energy required for conversion of biomass or waste to bio-oil, syngas, and biochar [51]. The difference between the activation energy and enthalpy values reflects the potential energy barrier in the pyrolysis process for formation of activated complex [52]. Small difference (about $5 \mathrm{~kJ} / \mathrm{mol}$ ) between the activation energy and enthalpy values calculated for cattle manure, recycled polyester and their blend are indicative of high feasibility of the pyrolysis and co-pyrolysis processes and ease in formation of activated complex. The enthalpy values of biomass were found to be similar to literature data for biomass and waste. In addition, positive values of enthalpy implied the endothermic degradation of the waste materials.

Calculation of pre-exponential factor (A) is critical for describing the reaction chemistry in the pyrolysis process. A-values lower than $10^{9} \mathrm{~s}^{-1}$ indicates formation of surface reaction. However, if the reaction is surface-independent, A-values smaller than $10^{9} \mathrm{~s}^{-1}$ determines a closed complex. On the other hand, A-values greater than $10^{9} \mathrm{~s}^{-1}$ represents a simpler complex [53]. In this study all the pre-exponential factor values have found to be greater than $10^{9} \mathrm{~s}^{-1}$ which have indicated the high complexity of the waste materials under consideration. As shown in Table 3, for cattle manure, pre-exponential factors have found to be within the range of $10^{10} \mathrm{~s}^{-1}$ to $10^{25} \mathrm{~s}^{-1}$ for recycled polyester the factors have changed in between $10^{14} \mathrm{~s}^{-1}$ and $10^{25} \mathrm{~s}^{-1}$ and for the blend the range of pre-exponential factors have got narrowed from $10^{13} \mathrm{~s}^{-1}$ to $10^{18} \mathrm{~s}^{-1}$.

Entropy $(\Delta S)$ is the indicator of degree of system disorder. Increase of entropy $(\Delta S)$ with conversion degree has observed in cattle manure degradation. This reflects higher reactivity of the system which reduces the time to form activated complex [4,22]. During recycled polyester pyrolysis entropy change has found to increase up to $60 \%$ conversion, and then has reduced. Entropy change of blend has shown variations and has conducted different behavior than the parent fuels.

The Gibb's free energy $(\Delta \mathrm{G})$ reflects the amount of available energy upon pyrolysis and co-pyrolysis. The average values of $\Delta \mathrm{G}$ were found as $150.73 \mathrm{~kJ} / \mathrm{mol}, 176.72 \mathrm{~kJ} / \mathrm{mol}$, and $174.62 \mathrm{~kJ} / \mathrm{mol}$ for cattle manure, recycled polyester, and their blend, respectively. The calculated $\Delta \mathrm{G}$ values have shown that pyrolysis and co-pyrolysis of the waste materials under consideration have a considerable bioenergy potential. Besides, the average value of $\Delta \mathrm{G}$ for thermal degradation of the blend were larger than that of cattle manure and almost equal to the value of recycled polyester. This has indicated the introduction of more energy during co-pyrolysis process compared to manure pyrolysis. 


\section{Conclusions}

The results of this study signify the importance of co-pyrolysis of cattle manure with recycled plastic wastes. The following conclusions may be drawn from results of this study:

(1) TGA plots demonstrate the existence of synergistic effect during co-pyrolysis of cattle manure and recycled polyester.

(2) The apparent activation energies $\left(E_{a}\right)$ of cattle manure, recycled polyester, and their blend were calculated by FWO method as 194.62, 254.22, and $227.21 \mathrm{~kJ} / \mathrm{mol}$, respectively.

(3) The average $\Delta G$ value of the blend ( $174.62 \mathrm{~kJ} / \mathrm{mole}$ ) shows highly available energy to be considered as a feedstock for green energy production.

Funding: This research received no external funding.

Acknowledgments: The author would like to thank Hande Çelebi and her staff members from Eskişehir Technical University for instrumental and technical support.

Conflicts of Interest: The author declares no potential conflict of interest with respect to the research, authorship, and/or publication of this article.

\section{References}

1. Teixeira, T.R.; Ribeiroa, C.A.A.S.; Santos, A.R.; Marcattic, G.E.; Lorenzon, A.S.; Castro, N.L.M.; Domingues, G.F.; Leite, H.G.; Menezes, S.J.M.C.; Mota, P.H.S.; et al. Forest Biomass Power Plant Installation Scenarios. Biomass Bioenerg. 2018, 108, 35-47. [CrossRef]

2. Tchapda, A.H.; Pisupati, S.V. A Review of Thermal Co-Conversion of Coal and Biomass/Waste. Energies 2014, 7, 1098-1148. [CrossRef]

3. Chen, L.; Wang, S.; Meng, H.; Wu, Z.; Zhao, J. Synergistic effect on thermal behavior and char morphology analysis during co-pyrolysis of paulownia wood blended with different plastics waste. Appl. Therm. Eng. 2017, 111, 834-846. [CrossRef]

4. Yuan, X.; He, T.; Cao, H.; Yuan, Q. Cattle Manure Pyrolysis: Kinetic and Thermodynamic Analysis with Isoconversional Methods. Renew. Energy 2017, 107, 489-496. [CrossRef]

5. Akyürek, Z. Potential of biogas energy from animal waste in the Mediterranean Region of Turkey. J. Energy Syst. 2018, 2, 159-167. [CrossRef]

6. Lazaroiu, G.; Mihaescu, L.; Negreanu, G.; Pana, C.; Pisa, I.; Cernat, A.; Ciupageanu, D.A. Experimental Investigations of Innovative Biomass Energy Harnessing Solutions. Energies 2018, 11, 3469. [CrossRef]

7. Beringer, T. Bioenergy production potential of global biomass plantations under environmental and agricultural constraints. GCB Bioenerg. 2011, 3, 299-312. [CrossRef]

8. Graham, J.P.; Nachman, K.E. Managing Waste from confined animal feeding operations in the United States: The need for sanitary reform. J. Water Health 2010, 8, 646-670. [CrossRef] [PubMed]

9. Carlin, N.; Annamalai, K.; Sweeten, J.; Mukhtar, S. Thermo-Chemical Conversion Analysis on Dairy Manure-Based Biomass Through Direct Combustion. Int. J. Green Energy 2007, 4, 133-159. [CrossRef]

10. Philip, J.M.; Aravind, U.K.; Aravindakumar, C.T. Chapter 5 Use of Antibiotics in Animals and Its Possible Impacts in the Environment. In Handbook of Research on Social Marketing and Its Influence on the Animal Origin Food Product Consumption; Bogueva, D., Marinova, D., Raphaely, T., Eds.; IGI Global: Hershey, PA, USA, 2018; pp. 77-91.

11. Kaygusuz, K.; Şekerci, T. Biomass for efficiency and sustainability energy utilization in Turkey. J. Eng. Res. App. Sci. 2016, 5, 332-341.

12. Das, P.; Twari, P. Valorization of packaging plastic waste by slow pyrolysis. Resources. Conserv. Recycl. 2018, 128, 69-77. [CrossRef]

13. Verma, R.; Vinoda, K.S.; Papireddy, M.; Gowda, A.N.S. Toxic pollutants from plastic waste-A review. Procedia Environ. Sci. 2016, 35, 701-708. [CrossRef]

14. Association of Plastic Manufacturers Europe (APME). An Analysis of European Plastics Production, Demand and Waste Data, 2017. Available online: https://www.plasticseurope.org/application/files/5715/1717/ 4180/plastics_the_facts_2017_final_for_website_one_page.pdf (accessed on 12 April 2019). 
15. Turkish Plastic Industry Research, Development and Education Foundation (Pagev), Packaging waste of Turkey. Available online: https:/www.pagev.org/turkiye-de-plastik-geri-donusumu-avrupa-nin-odaginda (accessed on 5 March 2019).

16. Lee, S.R.; Lee, J.; Lee, T.; Cho, S.H.; Oh, J.I.; Kim, H.; Tsang, D.C.W.; Kwon, E.E. Carbon Dioxide Assisted Thermal Decomposition of Cattle Manure. Sci. Total Environ. 2018, 615, 70-77. [CrossRef] [PubMed]

17. Wong, S.L.; Ngadi, N.; Abdullah, T.A.T.; Inuwa, I.M. Current state and future prospects of plastic waste as source of fuel: A review. Renew. Sustain. Energy Rev. 2015, 50, 1167-1180. [CrossRef]

18. Tripathi, M.; Sahu, J.N.; Ganesan, P. Effect of Process Parameters on Production of Biochar from Biomass Waste through Pyrolysis: A Review. Renew. Sustain. Energy Rev. 2016, 55, 467-481. [CrossRef]

19. Uzoejinwa, B.B.; He, X.; Wang, S.; Abomohra, A.E.F.; Hu, Y.; Wang, Q. Co-pyrolysis of biomass and waste plastics as a thermochemical conversion technology for high-grade biofuel production: Recent progress and future directions elsewhere worldwide. Energy Convers Manag. 2018, 163, 468-492. [CrossRef]

20. Volpe, M.; D’Anna, C.; Messineo, S.; Volpe, R.; Messineo, A. Sustainable Production of Bio-Combustibles from Pyrolysis of Agro-Industrial Wastes. Sustainability 2014, 6, 7866-7882. [CrossRef]

21. Chen, X.; Liu, L.; Zhang, L.; Zhao, Y.; Zhang, Z.; Xie, X.; Qiua, P.; Chen, G.; Pei, J. Thermogravimetric analysis and kinetics of the co-pyrolysis of coal blends with corn stalks. Thermochim. Acta 2018, 659, 59-65. [CrossRef]

22. Kaur, R.; Gera, P.; Jha, M.K.; Bhaskar, T. Pyrolysis kinetics and thermodynamic parameters of castor (Ricinus communis) residue using thermogravimetric analysis. Bioresour. Technol. 2018, 250, 422-428. [CrossRef]

23. Yang, H.; Yan, R.; Chen, H.; Lee, D.H.; Zheng, C. Characteristics of hemicellulose, cellulose and lignin pyrolysis. Fuel 2007, 86, 1781-1788. [CrossRef]

24. Islam, M.A.; Asif, M.; Hameed, B.H. Pyrolysis kinetics of raw and hydrothermally carbonized Karanj (Pongamia pinnata) fruit hulls via thermogravimetric analysis. Bioresour. Technol. 2015, 179, 227-233. [CrossRef]

25. Zannikos, F.; Kalligeros, S.; Anastopoulos, G.; Lois, E. Converting biomass and waste plastic to solid fuel briquettes. J. Renew. Energy 2013, 1-9. [CrossRef]

26. Zhang, X.; Lei, H.; Zhu, L.; Zhu, X.; Qian, M.; Yadavalli, G.; Wu, J.; Chen, S. Thermal behavior and kinetic study for catalytic co-pyrolysis of biomass with plastics. Bioresour. Technol. 2016, 220, 233-238. [CrossRef] [PubMed]

27. Alvarez, J.; Kumagai, S.; Wu, C.; Yoshioka, T.; Bilbao, J.; Olazar, M.; Williams, P.T. Hydrogen production from biomass and plastic mixtures by pyrolysis-gasification. Int. J. Hydrog. Energy 2014, 39, 10883-10891. [CrossRef]

28. Burra, K.G.; Gupta, A.K. Synergistic Effects in Steam Gasification of Combined Biomass and Plastic Waste Mixtures. Appl. Energy 2018, 211, 230-236. [CrossRef]

29. Jin, Q.; Wang, X.; Li, S.; Mikulcic, H.; Beseni, T.; Deng, S.; Vujanovic, M.; Tan, H.; Kumfer, B.M. Synergistic effects during co-pyrolysis of biomass and plastic: Gas, tar, soot, char products and thermogravimetric study. J. Energy Inst. 2019, 92, 108-117. [CrossRef]

30. Xiang, Z.; Liang, J.; Morgan, H.M., Jr.; Liu, Y.; Mao, H.; Bu, Q. Thermal behavior and kinetic study for co-pyrolysis of lignocellulosic biomass with polyethylene over Cobalt modified ZSM-5 catalyst by thermogravimetric analysis. Bioresour Technol. 2018, 247, 804-811. [CrossRef]

31. Xue, Y.; Bai, X. Synergistic enhancement of product quality through fast co-pyrolysis of acid pretreated biomass and waste plastic. Energy Convers Manag. 2018, 164, 629-638. [CrossRef]

32. Duangchan, A.; Samart, C. Tertiary recycling of PVC-containing plastic waste by copyrolysis with cattle manure. Waste Manag. 2008, 28, 2415-2421. [CrossRef]

33. Ansah, E.; Wang, L.; Shahbazi, A. Thermogravimetric and calorimetric characteristics during co-pyrolysis of municipal solid waste components. Waste Manag. 2016, 56, 196-206. [CrossRef]

34. Aboulkas, A.; Elharfi, K.; El Bouadili, A. Non-isothermal kinetic studies on co-processing of olive residue and polypropylene. Energy Convers Manag. 2008, 49, 3666-3671. [CrossRef]

35. Bernardo, M.; Lapa, N.; Gonçalves, M.; Barbosa, R.; Gulyurtlu, I. Toxicity of char residues produced in the co-pyrolysis of different wastes. Waste Manag. 2010, 30, 628-635. [CrossRef] [PubMed]

36. Brebu, M.; Ucar, S.; Vasile, C.; Yanik, J. Co-pyrolysis of pine cone with synthetic polymers. Fuel 2010, 89, 1911-1918. [CrossRef]

37. Zhou, H.; Meng, A.H.; Long, Y.Q.; Li, Q.H.Y.; Zhang, G. Interactions of municipal solid waste components during pyrolysis: A TG-FTIR study. J. Anal. Appl. Pyroly. 2014, 108, 19-25. [CrossRef] 
38. Özyuğuran, A.; Yaman, S.; Küçükbayrak, S. Prediction of calorific value of biomass based on elemental analysis. Int. Adv. Res. Eng. J. 2018, 2, 254-260.

39. Flynn, J.H.; Wall, L.A. General treatment of the thermogravimetry of polymers. J. Res. Natl. Bur. Stand. 1966, 70, 487-523. [CrossRef]

40. Ozawa, T. A new method of analyzing thermogravimetric data. Bull. Chem. Soc. Jpn. 1965, 38, 1881-1886. [CrossRef]

41. Chen, G.; He, S.H.; Cheng, Z.; Guan, Y.; Yan, B.; Ma, W.; Leung, D.Y.C. Comparison of Kinetic Analysis Methods in Thermal Decomposition of Cattle Manure by Thermogravimetric Analysis. Bioresour. Technol. 2017, 243, 69-77. [CrossRef]

42. Ahmed, I.I.; Nipattummakul, N.; Gupta, A.K. Characteristics of Syngas from Co-gasification of Polyethylene and Woodchip. Appl. Energy 2011, 88, 165-174. [CrossRef]

43. D'Almeida, A.L.F.S.; Barreto, D.W.; Calado, V.; D'Almeida, J.R.M. Thermal analysis of less common lignocellulose fibers. J. Therm. Anal. Calorim 2008, 91, 405-408. [CrossRef]

44. Fernandez-Lopez,I.M.; Gamero, L.P.; Lopez-Gonzalez, D.; Avalos-Ramirez, A.; Valverde, R.J.; Sanchez-Silva, L . Life cycle assessment of swine and dairy manure: Pyrolysis and combustion processes. Bioresour Technol. 2015, 182, 184-192. [CrossRef]

45. Chen, J.; Wang, Y.; Lang, X.; Ren, X.; Fan, S. Evaluation of agricultural residues pyrolysis under non-isothermal conditions: Thermal behaviors, kinetics, and thermodynamics. Bioresour Technol. 2017, 241, 340-348. [CrossRef]

46. Larraín, T.; Carrier, M.; Radovic, L.R. Structure-reactivity relationship in pyrolysis of plastics: A comparison with natural polymers. J. Anal. Appl. Pyrol. 2017, 126, 346-356. [CrossRef]

47. Yu, X.; Wang, S.; Zhang, J. Preparation of high adsorption performance activated carbon by pyrolysis of waste polyester. J. Mater. Sci. 2018, 53, 5458-5466. [CrossRef]

48. Tang, Y.; Huang, Q.; Sun, K.; Chi, Y.; Yan, J. Co-pyrolysis characteristics and kinetic analysis of organic food waste and plastic. Bioresour Technol. 2018, 249, 16-23. [CrossRef]

49. Al-Juaidiyah, J. Pyrolysis kinetics of recycled polyesters. Int. J. Cloth. Sci. Technol. 2015, 24, 523-531. [CrossRef]

50. Zheng, Y.; Tao, L.; Yang, X.; Huang, Y.; Liu, C.; Zheng, Z. Study of the thermal behavior, kinetics, and product characterization of biomass and low-density polyethylene co-pyrolysis by thermogravimetric analysis and pyrolysis-GC/MS. J. Anal. Appl. Pyrol. 2018, 133, 185-197. [CrossRef]

51. Daugaard, D.E.; Brown, R.C. Enthalpy for pyrolysis for several types of biomass. Energy Fuel. 2003, 17, 934-939. [CrossRef]

52. Ahmad, M.S.; Mehmood, M.A.; Taqvic, H.S.T.; Elkamel, A.; Liu, C.G.; Xu, J.; Rahimuddin, S.A.; Gull, M. Pyrolysis, kinetics analysis, thermodynamics parameters and reaction mechanism of Typha latifolia to evaluate its bioenergy potential. Bioresour Technol. 2017, 245, 491-501. [CrossRef]

53. Turmanova, S.C.; Genieva, S.D.; Dimitrova, A.S.; Vlaev, L.T. Non-isothermal degradation kinetics of filled with rise husk ash polypropene composites. Express Poly Lett. 2008, 2, 133-146. [CrossRef]

(C) 2019 by the author. Licensee MDPI, Basel, Switzerland. This article is an open access article distributed under the terms and conditions of the Creative Commons Attribution (CC BY) license (http://creativecommons.org/licenses/by/4.0/). 